\title{
PAEDIATRICS IN WESTERN NIGERIA
}

\author{
BY \\ MALCOLM MACGREGOR \\ Sometime Lecturer in Paediatrics, University College, Ibadan
}

(RECEIVED FOR PUBLICATION NOVEMBER 15, 1957)

\section{Introduction}

The aim of this article is to present to the reader a broad view of the work of a general hospital in West Africa in its relation to the health of children. Facts and impressions were accumulated by the author during a year's sojourn in Nigeria, too short a time no doubt for a penetrating survey of local problems, but, possessed of the clinical potential of a flourishing and well-esteemed young hospital, long enough for a responsible survey of the main topics confronting workers in Child Health in West Africa. Practice in Africa is bewildering and refreshing to an English doctor, and requires a fresh approach adapted to experiences in new realms of pathology.

Several published descriptions have focused attention on the University College Hospital, Ibadan, during its growth (vide British Medical Journal, 1956). Now it is completed and possesses facilities that are unexcelled in tropical Africa. Built beside a teeming Nigerian city, a centre both of commerce and administration, and closely in contact with a university already of considerable renown, the new hospital is exceptionally favoured in its circumstances and associations.

In the waiting period while the new hospital was being built, the medical staff, who were already assembled, were occupied in creating a corporate hospital unit and at the same time in providing the local population of Ibadan with the fuller medical services that such an unexampled mustering of doctors and nurses made possible. These new facilities were grasped with alacrity, and in no sphere more willingly than by parents for their children. It was during this interregnum that the subject matter of this paper was collected. The base hospital was then the Adeoyo Hospital in the middle of the old town, a group of single storied buildings closely encircled by primitive dwelling houses, recently vacated by the Ibadan District Council to furnish the nidus of the University Hospital organization. The little renovation that was possible was done, and soon this primitive and unkempt small hospital became imbued with a mood of energy and promise, so that its achievements far over-reached its material restrictions. The children's ward consisted of a congested room with a balcony, together able to contain some 35 infants and children under 12 years of age. In this ward fulminating gastro-enteritis was treated beside broncho-pneumonia, septic ulcers beside extensive exposed burns, typhoid beside malaria and tuberculosis amidst them all. The frequency of cross infection can only be roughly guessed, but was certainly not very great, as instanced by the fact that diarrhoea seldom developed in hospital even in long-stay patients. Perhaps we owed this to the sunlight and free circulation of air in a ward with constantly open doors and windows. An element of squalor is inseparable from work in these circumstances, but the first affronted reaction to bed linen grey from use and re-use, to the one ward lavatory of hole-in-floor type which served for patients, staff and visitors, to the 'sluice room', a square cell with a tap and a hole in the wall from which the effluent flowed outside in a rather illdefined way, and to the chicken which continued defiantly to inhabit the out-patient verandah, passed when one realized that these were unalterable but temporary conditions, and that ill results from them were so much less than might be imagined.

Social Aspects. Ibadan is the chief town of the Yoruba tribe by whom Western Nigeria is largely peopled. Easy-going, generous and intelligent, the Yorubas have constructed a community based upon peasant agriculture but centred upon towns. They live in urban concentrations often of considerable size, but for part of the year retire to their farms at a distance to work the land. Consequently there is a fluidity about the population, making census figures for an area inaccurate. Peasant society is largely polygamous and responsibility for wives and children is only partly borne by the husband, with the result that the women make themselves as far as possible economically independent by petty trading, for 
which they : possess enormous aptitude. Market stalls tended by blue-turbanned and vociferous womenfolk are a prime ingredient of Yoruba-land.

In Ibadan there are reputed to dwell some half a million people. It is a sprawling town of mudbuilt dwellings with corrugated iron roofs intermingled with substantial brick villas and modern emporia. It is fringed by a new growth of fine buildings in a modern tropical idiom, and by reservations of dwelling houses with extensive gardens. Open drains through the town convey sewage and stormwater. Ibadan streets at all times are a press of sound and life, thronged with pedestrians, bicycles and impatiently hooting motor traffic, a witness to the liveliness and vigour of its many-faceted society, which contains Indian, Lebanese and European communities as well as African.

Uncomprehending of the methods and beliefs of practitioners of Western medicine, the common people have, notwithstanding, been quick to recognize its capabilities, particularly since the advent of potent chemotherapeutic drugs. Attempts at rational exposition of the causes of disease and the aims of treatment encounter customs, fears, superstitions and taboos that among the illiterate are a complete bar to understanding. The following account of popular beliefs in Ibadan is based upon a recent article (Omololu, 1956). Diseases, Dr. Omololu says, are always caused by the wrath of spirits, by worms, or by the machination of enemies. Education modifies but does not efface this concept. The conception of micro-organisms causing disease has never been entertained in Yoruba-land. In a polygamous society the ground is fertile for suspicion and culprits are easily found. At a more advanced level, certain poorly-defined notions of pathology are used as comprehensive explanations of a wide range of disorders. A past history of urethral discharge, for example, is regarded as infallible evidence of gonorrhoea and may be held responsible for any urinary, joint or skin symptom. 'Black blood' may be regarded as the cause of an illness whose manifestations range from malaria to vitamin B deficiency and to impotence. A change of blood is indicated and a good doctor knows that injections rather than dietary advice or mixtures can best accomplish the change. It is well-known that injections are the most potent remedies available for almost anything.

Yoruba-land is extremely conscious of its gastrointestinal tract and in consequence any symptom arising from it is presented forthwith. A patient might fail to mention that he has dyspnoea, but not that he has a coated tongue or that he has vomited.
Diarrhoea, dysentery and piles are to the common people synonymous and may be used to denote anything from frequent stools to pruritus ani. One may never take it for granted that the patient has the slightest idea of the meaning of the word he is using; rather it is safer to assume that he is conscious of something amiss in a roughly specified region of the body. A person who complains of constipation for example cannot even be assumed not to have diarrhoea. Intestinal worms are almost omnipresent and the popular mind has conferred upon them an almost unlimited potential for evil. Any digestive upset, increased peristaltic movement, or irritation anywhere in skin or scalp is laid at their door.

The father is dominant in the Yoruba family and his availability and mood are important in deciding whether or not one of his children shall attend hospital. Whether he lives with the mother or not, his consent must be obtained before the child can be brought into hospital. If this is not done the wife by general consent can be divorced with ignominy. Generally speaking, in their devotion to their children, in their courage in breaking with the past, in their efforts to cooperate with doctors, whatever the difficulties, and in their uncomplaining tolerance of discomforts and delays, the young Nigerian mothers deserve measureless praise. For those better-educated girls, increasingly under the influence of English speaking cultures, who have made a monogamous marriage and are yet bonded by birth to a Yoruba manner of life, there is an intolerable conflict at every turn, especially in the raising of their children. A danger is that they will reject their heritage in favour of the meretricious attractions of suburban English culture.

Children are fed almost universally on the breast and lactation is a more abundant and more efficient process than in Britain, rarely attended by complications of engorgement or sore nipples. Manual expression of breast milk occasions no difficulty. At six months or after the output often decreases, and, as it is common to breast feed for one or two years, this is an important influence in retarding growth. Feeding at the breast is entirely on demand and the baby, slung in a girdle on his mother's back, is close enough to be sure that his needs are not overlooked (Fig. 1). Weaning, which occurs late, is likely to be to 'pap' (a paste of maize flour) with occasional meat soup (a dilute vegetable broth, not of much nutritive value, containing dried fish, peppers, palm oil and small quantities of meat). This diet is subsequently varied by the addition of yam and cassava, beans and plantains. Eggs and milk are not in the diet, nor are meat, fish or fresh fruit in any adequate 
amount. Consequently symptoms of protein deficiency are wide-spread and are aggravated when early withdrawal from the breast is necessary or if illness makes extra demands upon metabolism. Tradition as much as economics is responsible for this ill-balanced diet, and striking benefits are seen if parents can be prevailed upon to give preference to naturally-occurring rich protein foods such as beans, dried fish, ground-nuts and guinea corn, rather than to the time-honoured starchy yams and cassava. The admission of children to hospital has some educative value here and it is hoped that parents will profit from hospital precept and admonishment in the subsequent management of their children (Fig. 2).

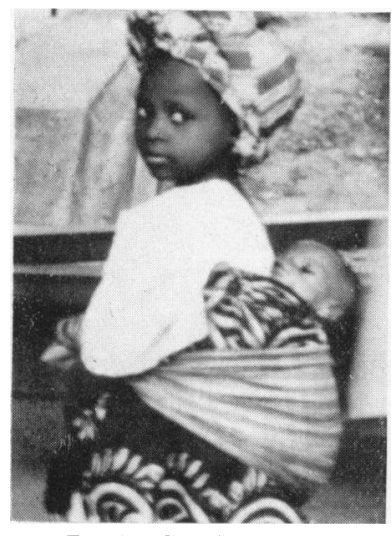

FIG. 1.-Carrying a baby.

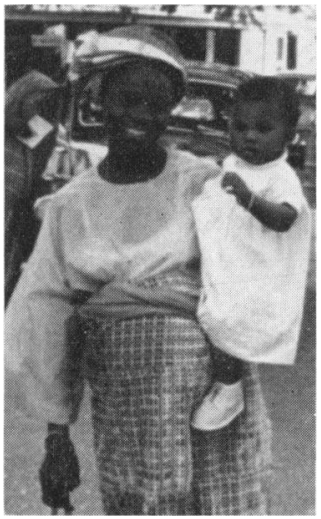

FIG. 2.-Mother and child from infant welfare clinic.
On the whole the Yoruba peasantry is a clean people and standards of personal hygiene are good despite the fact that some methods of child care, such as the early management of the umbilical cord, seriously conflict with European ideas. The babies are mainly overdressed, except for diapers which are non-existent among the uneducated. No attempt is made to inculcate early control of sphincters, which seriously complicates sanitary arrangements for large out-patient clinics. Messes of all sorts are disposed of rapidly by Yoruba women, usually being wiped up by some article of their own clothing; failing that, lifted by hand and thrown to the ground outside.

The educated section of the community is bilingual, English being used for everyday communication. Among the illiterates, the main source of the hospital attenders, an ability to speak English is exceptional. The language problem is further complicated by numerous minority groups from other parts of Nigeria, who dwell in and around
Ibadan. Yoruba is a difficult tonal language, requiring a flair to master it; a great part of the hospital work is carried on through interpreters. Although to work through an interpreter is probably less of a constraint in paediatrics, when histories are already at second hand, than in other branches of medicine, the intervention of a third mind is a great hindrance to speed and accuracy. Time-wasting confusion results from a search for detail, with the result that question and answer have to be reduced to rudimentary exchanges, paring away much that is valuable and that might facilitate diagnosis. Interpreters engaged in utilitarian repetitive conversations become desultory and inexact, or at worst provide the answers that they surmise the doctors are expecting. Sympathetic contact with the patients, so vital to indoctrination of novel ideas, is often a struggle to achieve and consultations can too easily become bleak and irritable under the twin pressures of haste and obscurity. Fortunately the strongly developed African sense of humour is often able to bridge the gap and to build an enduring bond of sympathy.

Statistics. The University College Hospital is a very busy one (Figs. 3, 4). If we take the month of August, 1956, at random, approximately 8,000 new out-patients attended the hospital and a quarter of these attended the paediatric department. In all, 23,000 out-patients came to the hospital during the month, and about 300 children attended daily. In the same month, 121 children were admitted to the 36 beds of the children's ward, as against 200 admissions to 131 adult medical and surgical beds in the hospital in the same period. There was therefore a relative preponderance of sick children.

During 1956, 1,881 children were admitted to the children's ward of Adeoyo Hospital. The diagnoses of these children are listed in Table 1, together with some figures concerning mortality. No less than $488(26 \%)$ of these children died. There were approximately 300 more males than females in this series and the male death rate $(24 \%$ contrasted with $28 \%$ ) was rather lower than the female. The male preponderance was considerably accentuated in admissions for tetanus, and for diarrhoea at all ages, whereas a significant female preponderance was evident in admissions for protein malnutrition.

When discussing the age distribution of the patients it is important to remember that statements of age by parents are very inaccurate. Dealing as we are with large numbers it is probable that inaccuracies in the one direction are roughly 


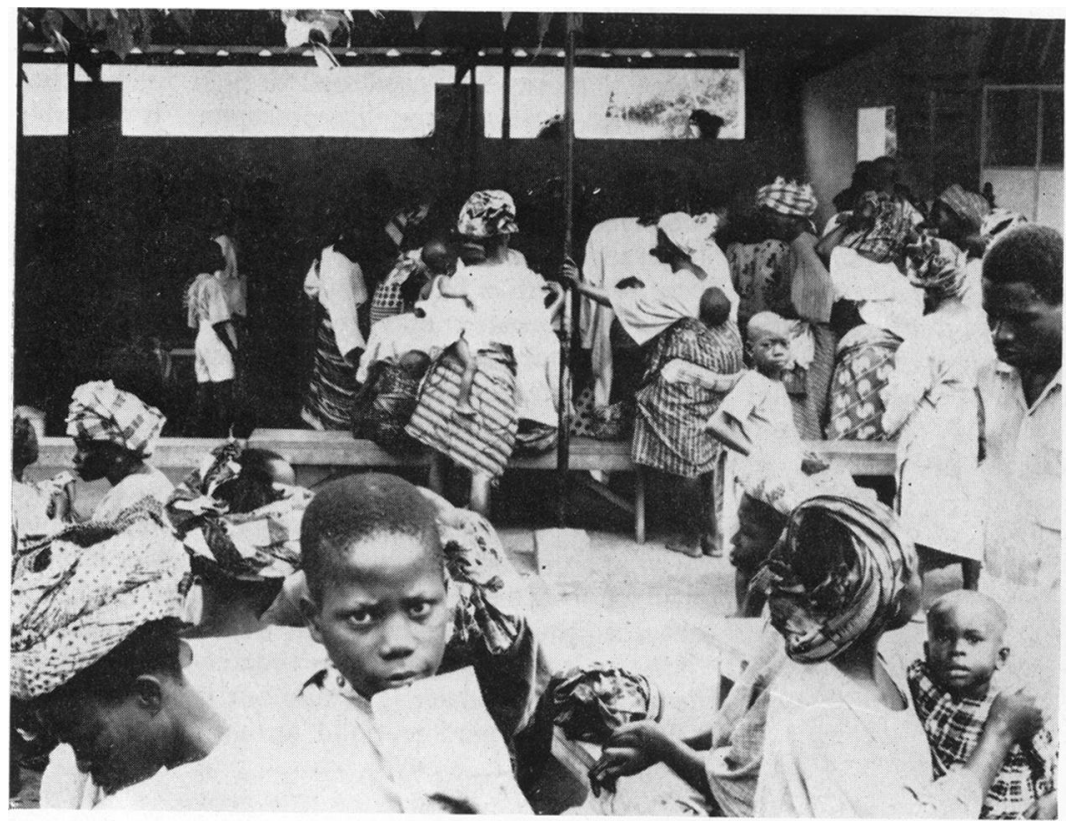

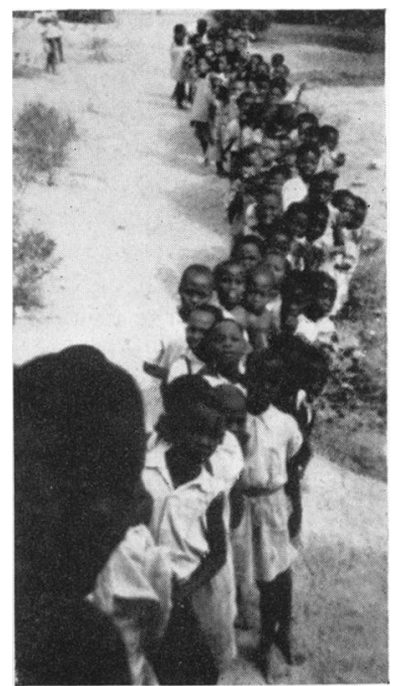

FIG. 4.- Waiting their turn.

FIG. 3.-Outside the Children's Clinic.

balanced by inaccuracies in the other, but the further one gets from birth, the more conjectural are the recorded ages. With this proviso, it appears that one half of the children were under 1 year old, one third between 1 and 3, and one fifth older than this. In this series the death rate according to age

TABLE 1

ADMISSIONS TO CHILDREN'S WARD, ADEOYO HOSPITAL, 1956, ANALYSED ACCORDING TO DIAGNOSIS. AND LISTED IN ORDER OF FREQUENCY

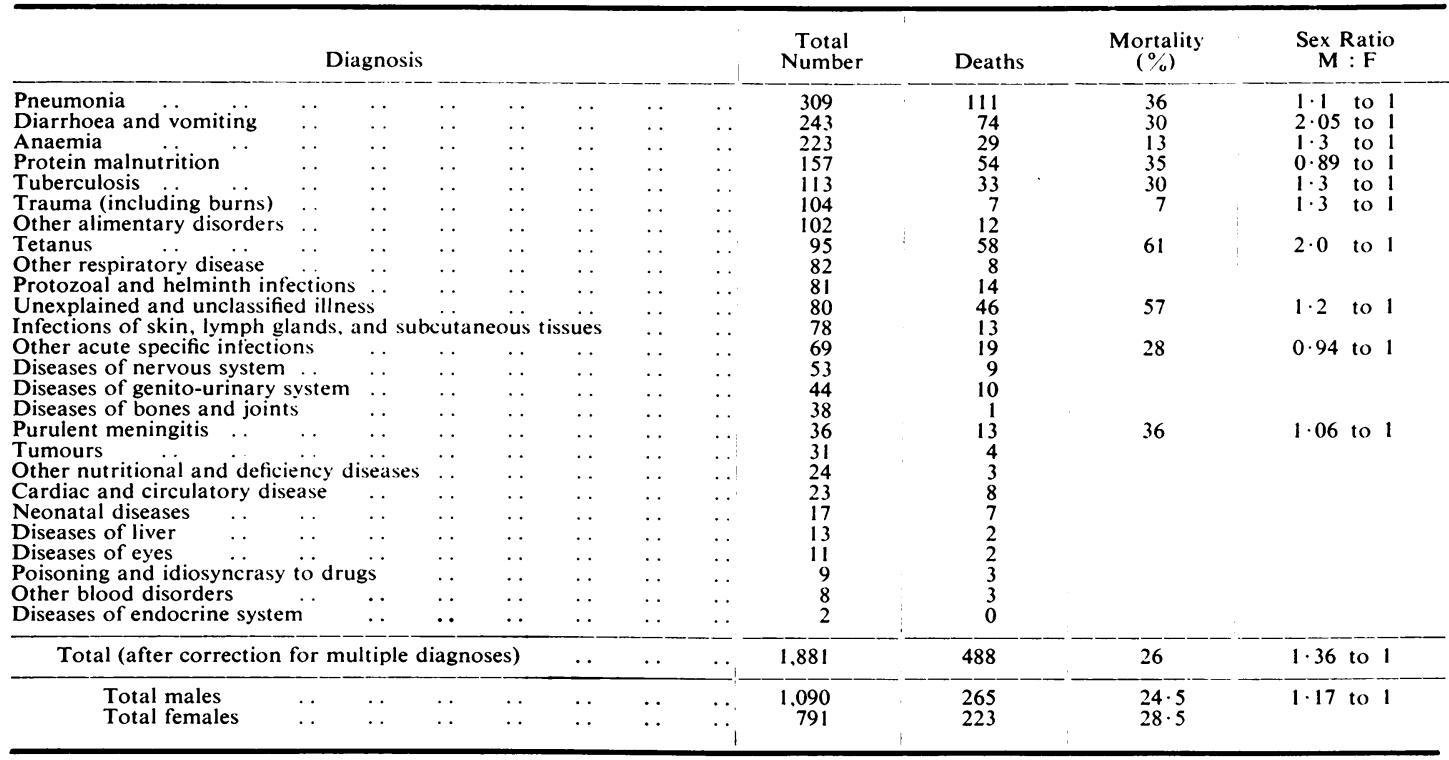


remained constant at $30 \%$ up to 6 years, and after that fell steeply. Just over one half of the total deaths occurred in infants (i.e. less than 1 year old).

Selection of Cases for Admission. Children were admitted nearly always for treatment, seldom for investigation only. A strict criterion was that, irrespective of diagnosis, the treatment could not be given as an out-patient. Priority was given to the desperately ill and to acute surgical emergencies. A few children from the surgical waiting list were admitted each week and a few others by the ophthalmic surgeon, gynaecologist and dermatologist from their clinics. The proportion of infants to older children was regulated to some extent by the number of infant cots available. The upper age limit was about 12 years, but was determined also by whether or not the child was too tall to lie comfortably in a small bed. Less direct influences were the willingness or otherwise of parents to accept admission (few in fact refused), and the reputation of the hospital for treatment of particular clinical entities. In general, where it is plain that treatment of a condition is effective, patients will come. The converse is also true. Geographical factors change the emphasis on certain diagnoses; Ibadan has a reputation as a healthy district, and the incidence of many diseases is undoubtedly greater elsewhere in Nigeria. On the other hand, community diseases such as tuberculosis and gastroenteritis may be unduly common in this huge congested township.

Examination of Patients. For the practitioner accustomed to fair-skinned children there is much to learn about the interpretation of physical signs of illness in Africans. Assessment of mucosal colour, jaundice, skin disorders, intelligence and indeed the recognition of an ill child all require experience. At first, judgment of a child's age is often at fault by as much as 3 years. Heights and weights grossly beneath the normal for the chronological age are very common (Fig. 5). Walters (1956) found that children in Ilobi, a village in South West Nigeria, were some $10 \%$ shorter in height than English children and that over the first 5 years of life they were about $20 \%$ lighter in weight. Racial differences in physique play a part in this, but undoubtedly more important in keeping the children back are undernutrition and ill-health. Children attending out-patients for example might have weights of $15 \mathrm{lb}$. or even less at the age of 3 or 4 .

Many African children, of course, especially those from better homes, are at every age physically comparable with European, and it is perhaps just this spread from super-normality to the most remarkable physical retardation that makes age assessment so difficult. Newly born babies are also small, with birth weights averaging $1 \mathrm{lb}$. or so below what is customary in England. Their range of skin colour is very great, and includes a shade of yellow-brown difficult to distinguish from a rather deep neonatal jaundice. Certain common symptoms of childhood carry different implications in Nigeria from those they have in Britain. Pallor for example is likely to be due to malaria or to sickle cell anaemia, oedema to protein malnutrition or nephrosis, abdominal pain to dysentery or ascariasis, jaundice in the newborn baby to septicaemia, and in the older child to a crisis of sickle cell disease, while convulsions, one of the commonest reasons for seeking help, are much more ominous than they are here. In the respiratory field alone is the range of diagnoses closely comparable to that in England. An enormous morbidity from whooping cough, bronchopneumonia and tuberculosis is common to the children of both countries.

The death rate in the children's wards is horrifying by European standards and exceeds the total of deaths in all other departments of the hospital.
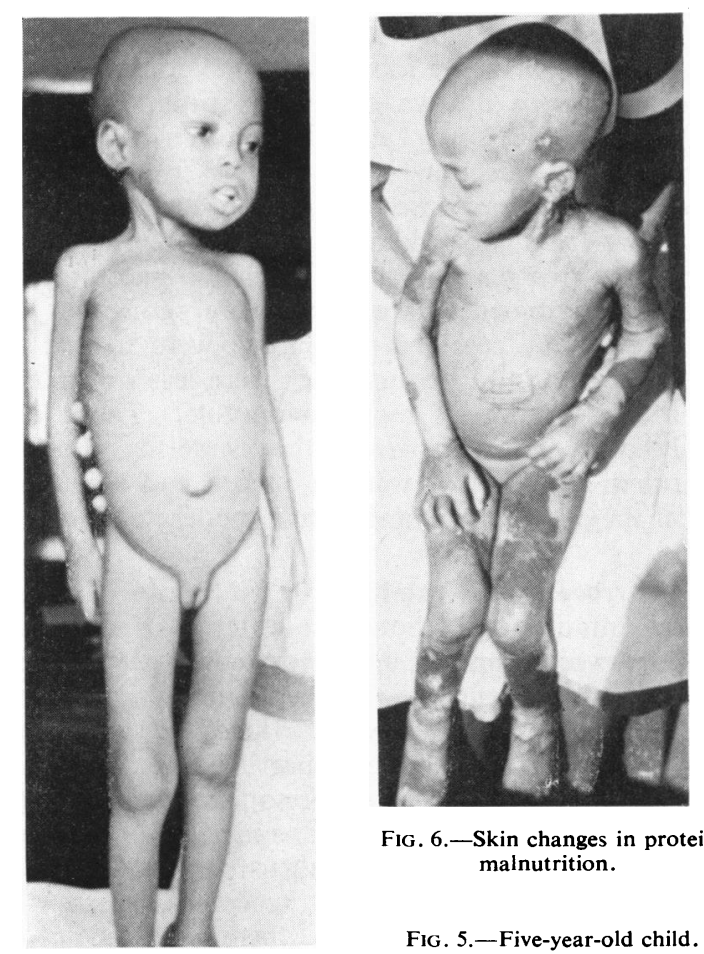

FIG. 6.-Skin changes in protein malnutrition.

FIG. 5.-Five-year-old child. 
The greater number of deaths occur within 24 hours of admission, and malnutrition, gastro-enteritis, broncho-pneumonia and tuberculosis account for most of them.

\section{Clinical Discussion}

There follows a commentary upon the illnesses that were encountered. They are considered under the headings, and in the sequence, of Table 1.

Pneumonia. This was the commonest reason for admission to hospital and was the greatest single cause of death in the whole series. Two thirds of the cases were in infants, and of the remainder most were in the 1 to 3 year age group. Among the latter, the mortality was even higher than in infants, probably because this is also the age group of protein malnutrition. A bacteriological diagnosis was not often made, but most cases were believed to be broncho-pneumonia of the usual catarrhal origin. Staphylococcal aetiology was inferred on several occasions because of the radiographic appearances. A short fulminating illness, often accompanied by diarrhoea, was the most common mode. Some of the patients in whom the illness ran a more protracted course may have been suffering from whooping cough. The prevalent local method of force-feeding weakly babies by hand certainly accounted for some aspiration pneumonias. Convulsions were always of serious prognosis; they were not obviously due to oxygen lack, and meningeal infection was always excluded. A better clinical response to one antibiotic rather than another was not demonstrated, and the most frequent treatment was with penicillin and streptomycin combined. Two cases were mongols.

Very many cases of pneumonia were treated as out-patients, and because they were less severe the outlook was much more favourable. Those admitted to hospital were either suffering from a virulent infection or were in such a bad condition that they could not stand even a moderate illness.

Diarrhoea and Vomiting. Two thirds of these were infants, and about a quarter of them died. Many were admitted in an extremely dehydrated state. Gastro-enteritis following upon prolonged underfeeding frequently provided us with an emaciated child to whom diarrhoea was the last straw. Nevertheless, one cannot feel content with the results of hospital management of gastroenteritis. The diarrhoea itself usually ceased fairly quickly with the usually accepted regime of parenteral fluids and chemotherapy. Electrolyte disturbances were corrected, but in many cases the child remained gravely ill and perished on the third or fourth day at a time when hydration was adequate and the known biochemical disturbances had been fully corrected. Much thought was given to the reason for these failures, and vitamin deficiency, hypocalcaemia, adrenal failure and hypoglycaemia were all excluded after experiment. Profound cerebral effects seemed to follow dehydration in many of these babies, who would have convulsions and subsequently remain in a blank immobile state with alteration in muscle tone and a tendency to muscle twitching which was ominous and not properly understood. Lumbar puncture was unrevealing. A number suffered from tetany during the recovery phase, and when tested, the serum calcium was found in such cases to be low. Pathogenic organisms were scarcely ever isolated from the stools, and the bacteriology of infantile gastro-enteritis in Nigeria has not yet been properly classified. As already remarked there was a striking preponderance of males among these patients.

Diarrhoea is probably the commonest symptom with which a young child is brought to hospital. Most out-patients were not very ill, and could be quickly restored by simple treatment, in practice usually a kaolin mixture and an anti-malarial drug. The majority were probably in fact symptomatic diarrhoeas, and not true enteric infections. Others, of course, were suffering from protein malnutrition, and usually revealed themselves as such by their failure to improve and by other signs. True bacillary dysentery was not uncommon in outpatients and responded so well to sulphonamides that such cases seldom got into hospital.

Anaemia. The infants in this group were usually suffering from some respiratory or alimentary illness, and were discovered because of their extreme pallor. Babies with haemoglobin levels of from $10 \%$ to $40 \%$ were admitted and transfused. They did very well, spending only one night in hospital in most cases, and seldom seemed to require further replenishment. The nature of the anaemia is unsolved. Dr. R. Hendrickse has studied these Ibadan babies with particular attention, and is of the opinion that in most of them the anaemia is due to the effects of malaria. It is doubtful if it is due to haemolysis alone, and there must be an individual idiosyncrasy as these cases were random among infants in the same environment and exposed to the same risk. Their nutritional state seemed irrelevant. The anaemia was usually normochromic, and iron deficiency, although it was not 
excluded by serum iron levels, is probably not an important contributory agent. Most were less than 6 months old. Dr. Hendrickse found that some of them could be made to reconstitute their own haemoglobin without transfusion, if they were given anti-malarial drugs only. Combination with broncho-pneumonia was common and accounted for some of the deaths. Others died because their anaemia was too profound to be treated in time, and one or two died of the cardio-vascular effects of transfusion.

In older children the aetiology was mixed: iron deficiency, post-infective anaemia, malarial anaemia and no doubt certain cases of sickle cell anaemia, although we have tried to classify these separately. As already mentioned, protein malnutrition does not seem to be a cause of profound anaemia in this population.

No less than 53 cases of sickle cell anaemia were admitted during the year. They were fairly evenly scattered in age throughout childhood. Most of them were admitted in crisis, that is to say with a low haemoglobin, fever and a tinge of jaundice, and with pain or even swelling around the joints. The blood often showed a high leucocytosis with a high nucleated red cell count. The spleen was large and sometimes tender. The swellings around the bones were sometimes inflammatory and this was especially true of the spindle-shaped swellings of the fingers and toes from which pus due to a salmonella organism was sometimes extracted. Jaundice seemingly of an obstructive type occurred in a number of these children, most probably due to a hepatitis. The diagnosis of sickle cell anaemia was confirmed by finding in the laboratory sickling of all red cells within 24 hours, accompanied by a filamentous form of red cell distortion. More accurate diagnosis was obtained by electrophoretic identification of the haemoglobin. There was further support for the diagnosis in the skull contour and in characteristic $x$-ray alterations in the trabeculation of the bones, although these signs were not invariable. A family history was also helpful. In Western Nigeria the incidence of sickle cell trait is $24 \%$, while sickle cell anaemia occurs in $0.3 \%$. The combination of sickle cell haemoglobin and haemoglobin C occurs in $1 \%$.

We performed Tallquist haemoglobin estimations whenever children seemed unduly pale. Much anaemia of intermediate severity was treated empirically with chloroquine and iron, and a response could be obtained in most cases. In Ilobi, Walters (1956) found haemoglobin averages of $9 \cdot 2 \mathrm{~g} . \%$ in the 0 to 1 year age-group, and of 10 to $11 \mathrm{~g} . \%$ in the 2 to 9 year age-group.
Protein Malnutrition. Although this figured only as the fourth commonest reason for admission, it was in many ways the most important disorder that we were called upon to treat because of its high mortality and its extreme prevalence in less severe forms, and also because it is preventable. The peak period for the disturbance is between 1 and 3 years, and more than half our in-patient examples fell into this age-group. A quarter of them were between 3 and 6, and only 14 were under 1 year old. After 6 years the incidence fell away sharply. The older children showed a slightly higher death rate, and at all ages a preponderance of females was noticed and this was not explained. Protein malnutrition formed a backcloth to all the illness we treated during the year; minor evidence of it was continually noted, and it was not used as a primary diagnosis unless the disease was gross. Even among this group, accompanying diseases figured largely. Pneumonia, tuberculosis, diarrhoea, anaemia and sepsis were the most important of these.

Early manifestations of the disease were oedema of the feet, and lassitude and fretfulness with some diarrhoea. Changes in the pigmentation of the skin came next (Fig. 6), and an extension of oedema. There might be some discolouration of the hair. In bad cases there was gross generalized oedema tending to spare the serous cavities, and a typical mosaic dermatosis on the limbs.

Some other bad cases were miserably emaciated with trophic skin changes but without oedema. In every case there were the characteristic hypoproteinaemia and dietary history as confirmatory points. Persistent watery diarrhoea, common to nearly all cases, aggravated their ill-health. Anaemia, though sometimes gross, did not seem to be a constant symptom, and a haemoglobin level of about $60 \%$ was average. These were most unpredictable children to treat, many dying suddenly during the first week in hospital. There would often be no warning of this, and one would be surprised to find that a child who was apparently improving had died during the night. There was a particular tendency to die within the first $\mathbf{4 8}$ hours after admission, which seemed greater than could be accounted for by the fact that these children were brought to hospital only when they were in an advanced stage of the disease. Treatment consisted of a graduated introduction of high-protein milk; graduated because too early feeding with concentrated protein exaggerated the diarrhoea and worsened the condition. Nevertheless, we have wondered if the abrupt change from their native high carbohydrate diet to this thin, semi-fluid one played a part in the early death of some of these 
cases. Education of parents in the best use of available foods was also a vital part of treatment.

Those who did not die improved quite rapidly and had a diuresis at about the end of the first week, and there was subsequent weight gain and restoration of vigour. Many were able to go home at the end of the second week, and were followed up at a Nutrition Clinic. The importance of routine radiographs of the chest in these cases came to be recognized because many of them, even though infected with tuberculosis, failed to give a positive tuberculin reaction in their malnourished, anergic state.

Tuberculosis. Tuberculosis is the commonest reason for admission of patients to the adult medical wards, but only comes fifth in frequency in children. It is, nevertheless, a serious and important disease, as witnessed by the 113 cases who were admitted during 1956. Pulmonary primary infection was, of course, far and away the commonest manifestation, and the brunt of the severe infections fell on young children. There were 17 cases of tuberculous broncho-pneumonia and four cases of miliary tuberculosis among this group. An association with protein malnutrition was common, and the two diseases together are a serious hazard to life. Tuberculous pleural effusion does not seem to be very common, and only two in hospital (and two other out-patients) developed this complication. There were three cases of tuberculous pericarditis with effusion, and one of tuberculous polyserositis. Abdominal tuberculosis, mainly the ascitic form of peritonitis, contributed 10 cases, and one of these showed a pseudo-chylous effusion.

Meningeal tuberculosis seemed to affect a lower age-group than is customary in the United Kingdom. Half of the cases were under 1 year old. Our cases of meningitis did very badly in spite of the use of all forms of chemotherapy, and in many cases cortisone as well.

It is a clinical impression that the glandular element of the primary complex within the chest assumes larger proportions than with English children. Very considerably broadened mediastina were common, but parenchymatous infiltration in the lung was frequently inconspicuous.

Tuberculous superficial lymphadenitis did not account for many admissions, but we noticed a proneness to large axillary tuberculous buboes, apparently not due to a superficial skin focus in the affected limb; in fact many had co-existing disease in the chest. Superficial tuberculosis seems very uncommon, which is the reverse of what one would expect, seeing that so many children have skin sores, and so many adults have open tuberculosis.
In considering tuberculous bone disease one notices at once the remarkable preponderance of Pott's disease of the spine. This accounts for the majority of tuberculous bone lesions at all ages, and begins sometimes in infancy. Spinal caries admitted to hospital had nervous complications as a rule. In such cases, costo-transversectomy with evacuation of paraspinal abscesses was often performed. The prognosis for return of nervous function below the site of disease was quite good in reasonably early cases, though some paraplegia proved irreversible. The policy adopted by Mr. P. Konstam, who was in charge of the surgical management of most of them, consisted in partially immobilizing the spine in a plaster of paris jacket and then treating the child as an ambulant outpatient, unless nervous complications were present. At the same time, of course, the child received chemotherapy. The results of this regime are to be the subject of a report by Mr. Konstam, but it may be said that these simple measures have been rewarded with striking success, and that firm healing with abundant perispinal calcification is achieved in a comparatively short time. Isolated cases of tuberculous hip or knee disease were seen, but were not common.

In a seven-month period, August, 1956 to February, 1957, 253 new children were referred to the weekly tuberculosis clinic. Of these 158 were deemed to have active tuberculosis. A number of other children who were referred to a surgical tuberculosis clinic with glandular or bone lesions, have escaped this inventory. Post-primary lung lesions were present in 11. Phlyctenular conjunctivitis seems to be a common addition to the tuberculous picture, and once established the tendency to reactivation with intercurrent infections persists for a long time. A good deal of corneal damage in children is caused in this way. On the other hand erythema nodosum was seen only twice in the year. Suspicion of a false positive Heaf test was created in five cases, all in very young children in whom after considerable observation no evidence of tuberculosis infection past or present could be found. The Heaf test in each case was positive Grade I. Non-specific tuberculin reactions have been discovered as causing confusion in the Heaf testing of African children, and the subject is discussed by Henshaw (1955).

If disease of the same severity is compared, these Nigerian children with tuberculosis appeared to progress under treatment at least as well as English children. Out-patient chemotherapy was used for all cases of primary tuberculosis with symptoms. Streptomycin was reserved for the more seriously 
ill, so that P.A.S. and isoniazid were given to the majority. It was gratifying to see the rapid reduction in toxaemia, and the gain in weight. Conditions were such that investigation of contacts could not be carried out.

We carried out a small study of children attending the general out-patients at the Adeoyo Hospital. New cases were Heaf tested on their first attendance and the result read three days later. Results were only obtained on 350 children. The proportion of Heaf positives was as follows:

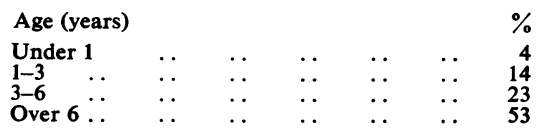

These were of course ailing children and a highly selected group, but the sample affords some indication of the level of primary infection in the Ibadan population.

Trauma. Burns and scalds, the most important diagnosis under this heading, made a considerable contribution to the work of the children's ward. The 47 cases in the year were evenly distributed over the ages up to 6 years; there were few after that. Most occurred around the domestic hearth, from clothing catching alight or more often from scalding fluids falling upon the children. A small group was due to a local method of reviving cáses of convulsions by hot applications to the feet. Management of burns in the open ward might be expected to lead to serious cross-infection, but in fact this was not so. They were treated by the open exposure method and early skin grafting was carried out where necessary. The incidence of complications was surprisingly low, undoubtedly lower than it would be in an open ward in the United Kingdom. In part this may be due to the rarity of the streptococcus. Blood transfusions were necessary for many of these children, and all of them were nursed under mosquito netting to keep off flies. Four died, a mortality of $8 \%$. Some remained in hospital for relatively long periods of six to eight weeks.

Other Alimentary Disorders. Between 1 and 6 years of age many Ibadan children suffered from cancrum oris. The disease starts as a marginal gingivitis with bleeding gums, after which infection encroaches upon the bony alveolus. A destructive osteomyelitis of the jaw begins and the infection then spreads outwards from this area to contiguous soft tissues, which are eroded. Within a matter of a few weeks there may be a large necrotic area which continues to extend until checked by treatment. The process responds very sensitively to penicillin and extension ceases as soon as this treatment is begun. Nevertheless, a long time is necessary for separation of the dead tissues, which may include a large bony sequestrum, as well as soft tissues sometimes composing the whole thickness of the lip or cheek. Great deformity arises therefore in some children who have been treated for severe cancrum oris, and the plastic repair of this is formidable. Most of the children with cancrum are in a state of reduced nutrition and may be anaemic, but the process itself does not seem to cause much, if any, general illness. In out-patients many children are seen with the premonitory symptoms of cancrum oris, namely bleeding gums, foetor oris and marginal gingivitis, and these symptoms can be brought to an end quickly with a few procaine penicillin injections.

A common surgical condition is intussusception, which in Nigeria mainly affects boys aged from 3 to 10 years. The symptoms are those of subacute intestinal obstruction and it is readily diagnosed and corrected.

Among other conditions that call for comment were five cases of Hirschsprung's disease. This disorder is evidently one that must be taken account of in Nigeria. On the other hand congenital intestinal atresia was only seen twice. Several cases of partial aplasia of the abdominal musculature, without renal abnormality, were seen and may be related in cause to exomphalos, which was observed to be one of the commoner congenital malformations, and to umbilical hernia which is very prevalent indeed. During the year, there was only one case of appendicitis in a child and no case of congenital pyloric stenosis.

Tetanus. Tetanus was the third greatest cause of death in children in this hospital series. In the adult medical wards this disease is the chief cause of death by a considerable margin. Neonatal tetanus comprised two thirds of our total cases. A very large number of infants born in hospital go home within a few hours, and are therefore submitted to the same methods of cord dressing during the early days of life as befalls those born at home. Nevertheless none of our babies with tetanus were born in hospital, and this suggests that liability to this disease depends upon the way in which the cord is severed at birth, and not upon the applications subsequently used. The mortality in newborn babies with tetanus was $77 \%$. Mortality rates are closely related to the day of life on which the first symptoms develop (Fig. 7). 
Various regimes of treatment for the newborn were tried through the year, some elaborate, some fairly simple. We still seek a simple routine of universal application which does not require exacting nursing or vigilant medical observation. Most of the deaths occurred after the first few days, the infant entering upon a cold, inanimate, oedematous state with shallow respirations. Another mode of dying occurred during the third week, with a high swinging temperature and finally hyperpyrexia.

Only a quarter of older children with tetanus died, and the risk of death became progressively less with increasing age, up to adolescence. It was often difficult to decide upon the site of entry of the tetanus organism. Chronic otorrhoea was several times suspected to have given access to tetanus.

Active immunization of the population has not been started. Anti-tetanic serum is used routinely in out-patients for wounds and abrasions. We saw a death in a child from anaphylaxis after this.

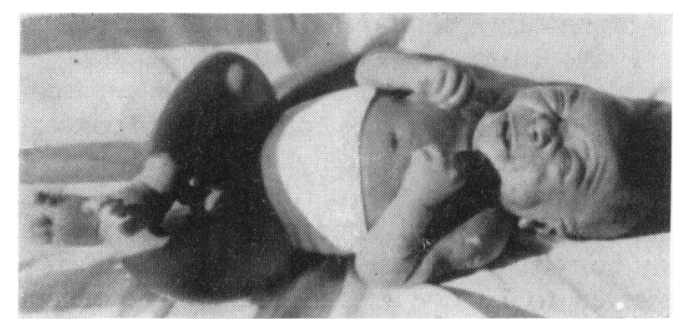

Fig. 7.-Neonatal tetanus.

Other Respiratory Disease. Retropharyngeal abscess was a condition of which we had to be continually mindful; there were seven cases in the year. Another interesting entity was a hyperacute pharyngitis with a plentiful soft yellow exudate, grave toxaemia and pronounced cervical adenitis with neck swelling. Although these cases (of which we had three, all of whom died) so closely resembled diphtheria, this organism was not isolated from any, nor in fact was any organism incriminated. In one, exudate appeared to involve the larynx and a tracheotomy was performed with temporary relief.

The common cold and upper respiratory disease generally (with the exception of otorrhoea) were not much of a problem. Chronic nasopharyngitis in children, so familiar in England, was practically never seen. Sinusitis was rare. The brunt of the widespread respiratory catarrhs fell upon the bronchi and lungs.

Both acute otitis media and otitis externa are common among Ibadan children of all ages. Recurrent otorrhoea with chronic perforation of the drums is one of the more frequent reasons for attendance. The discharge can be suppressed in most cases by a week of procaine penicillin, to obtain which they come to out-patients. There were many cases also of acute laryngitis, and tracheotomy cases were a commonplace. Chronic respiratory illnesses, whether asthma, bronchiectasis or fibrotic lung were scarce.

Protozoal and Helminth Infections. The incidence of malarial parasitaemia in random samples of the population is fairly accurately known in this area; for example Walters (1956) found in Ilobi the following percentage of malarial parasitaemia:

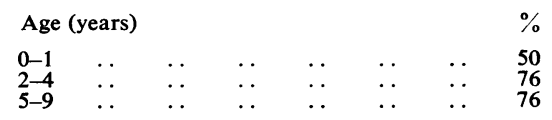

$P$. falciparum was far the commonest, and a mixture of $P$. malariae and $P$. falciparum next. Occasional $P$. ovale infections were seen. The adult parasite rate was approximately $30 \%$. In Ibadan school children, Garlick (1956) found in the age group 5 to 7 years, $84 \%$ parasitaemia (77\% falciparum, $20 \%$ quartan and $3 \%$ ovale; the number of mixed infections was considerable). In out-patient work with children, malaria is very common and heavy parasite densities even in infants were frequently discovered. Infection was quickly overcome with treatment. Patients ill from other causes often also developed malaria and one had to be ready to accept a sudden temperature as an indication for anti-malarial treatment in children in and out of hospital.

Though it is clearly desirable, it was not found possible in 1956 routinely to stain blood films of all children with fever on admission to hospital. It follows therefore that a majority of the cases classed here as malaria were clinical, or presumed, and this presumption was based on a rapid subsidence of symptoms after anti-malarial treatment. A common story was fever and convulsions of sudden onset in a young child, who was semicomatose and collapsed when admitted. Response to chloroquine was dramatic and consolidated the clinical diagnosis. Although an initial convulsion is common with a malarial infection, true cerebral malaria in a child was not proved to my satisfaction in any case. 
Amoebic dysentery was not very common among Ibadan children, but, when present, was usually the cause of severe illness. There were in fact seven deaths in 16 cases. There were only two cases of amoebic hepatitis.

Ascaris infestation is almost universal and seems to cause very few symptoms unless the child is unfortunate enough to become obstructed by a mass of worms in the intestine. This happened twice in this series and both children required laparotomy and worm removal. Whether the abdominal pain that is a common complaint in out-patients is ever related to ascaris infection is debatable. There seems little point in eradicating average worm infestations because of the certainty of return within a short time in this environment. Stool examinations were made on only a few in-patients, and neither there nor in routine reports on outpatients were the ova of hookworm (unlike round and whip-worm) frequently mentioned. This infestation does not appear to be a significant factor in the common anaemias of Ibadan children. Guinea worm is common but there is no effective hospital treatment. For this reason perhaps, fresh cases of guinea worm were not often seen, but late effects, such as abscess formation, sterile cystic collections around the track of the worm, cheloid scarring and sometimes radiographic demonstration of calcified guinea worms were noted many times.

Unexplained and Unclassified Illness. The frequency of obscure and fatal illness is one of the most tantalizing aspects of tropical paediatric practice. Fever with repeated convulsions and ensuing coma was a particularly familiar grouping of fatal symptoms. Such cases, if they did not rapidly respond to anti-malarial drugs, had a bad prognosis. Meningitis was excluded in all of them. In a number necropsies were performed without finding a cause for death. The picture was clinically that of acute encephalitis. More than half these cases died.

Infections of Skin, Lymph Glands and Subcutaneous Tissues. Superficial septic infections were a very important cause of morbidity in children. Of this group of 64 hospital in-patients, one third were newborn infants. In these the complications of umbilical sepsis were the main trouble. It can be truly said that trivial umbilical infections were not often seen, but that dangerous infections were not infrequent. Cellulitis spreading from the navel, and sometimes extending into the pelvic tissues, occurred 11 times and tended to be fatal. E. coli was the usual pathogen. Another form of cellulitis that was seen in babies affected the scalp, spreading with alarming rapidity to produce islands of necrosis of the whole thickness of the scalp, leaving large raw areas to be repaired.

At all ages, these children are very subject to multiple subcutaneous abscesses. So-called acute pyomyositis, from which a bacterial causative agent can rarely be recovered, was seen only once; it is a condition mainly confined to young adults. There were two cases of a curious low-grade retro-orbital cellulitis which were not satisfactorily explained or treated. A suppurative lymphadenitis of the iliac glands was a disabling and not unusual condition.

Staphylococcus pyogenes was responsible for the great majority of these septic conditions. Among in-patients it was found in 1956 that $60 \%$ of the staphylococci in the Adeoyo Hospital were resistant to penicillin, and among out-patients $35 \%$. About a quarter of in-patients and one seventh of outpatients, moreover, were infected with aureomycinresistant strains of staphylococcus.

In out-patients, skin sepsis of all kinds accounted for as many attendances as any other condition. Furunculosis about the head and shoulders, to which infants seem especially susceptible, impetigo, pemphigus, cellulitis and abscesses of all kinds were commonplace. Fortunately the in vivo response to penicillin seemed better than would be expected from the laboratory figures for drug sensitivity, and most skin sepsis could still be controlled quickly by a daily injection of procaine penicillin for three to four days, supplemented where necessary by incision. Among older children, tropical ulcers around the ankles (Fig. 8), with moist red bases and

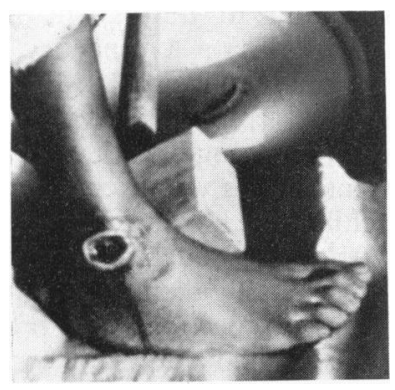

Fig. 8.-Tropical ulceration.

exuberant edges, were very common, and although no specific organism was isolated, the response to penicillin and eusol dressings was favourable and rapid.

Other Acute Specific Infections. Organisms of the Salmonella genus appear to be widespread in the 
Ibadan area, and can be recovered from a number of domestic animals and from lizards. We encountered infections at all ages in childhood. Clinical presentations varied from very subacute to the most severe illnesses. There were seven proven cases of infection by B. typhosus, and three of these died. Salmonella was recovered from certain cases of septicaemia in infancy, at which stage it is one cause of infective jaundice of the newborn.

Possibly the most interesting group were those five cases (all of whom were under 18 months old) who had a salmonella osteitis. Other examples were seen among out-patients. This is a lesion almost confined to young children with sickle cell anaemia. The bones chiefly affected were the small ones of hands and feet; in two the scapula was involved. A feature of this osteitis was its quiet presentation, and the absence of any systemic illness. The disorder appeared to be self-limiting and recovery complete. A typical $x$-ray picture in which osteolysis predominates can probably be recognized. This association has been reported before in the Belgian Congo, in Jamaica and in the United States, vide Golding (1956).

Whooping cough was the only one of the common infectious diseases of English children that proved at all common in Ibadan during 1956. Those admitted nearly all had broncho-pneumonia and ran a long course; they were mainly infants. Several infants severely ill with whooping cough developed an encephalopathy which was usually fatal. Such a child would have convulsions, with steadily diminishing awareness and a progressive rigidity of the limbs. The cerebrospinal fluid was normal. Two points were helpful in out-patient diagnosis of whooping cough. First, a tendency to a more generalized oedema than is usual in English children with a paroxysmal cough. Secondly, a tendency to haemoptysis, presumably due to rupture of pharyngeal veins. This was a common reason for bringing a child to hospital, and was almost diagnostic of whooping cough. Cases of secondary yaws were occasionally seen in out-patients, but positive Wassermann reactions were present in only $0.8 \%$ of the age group 5 to 9 years, contrasted with $8 \%$ in a group of adult males. No case of clinical syphilis was identified.

Diseases of Nervous System. Bizarre syndromes suggesting acute encephalitis were frequent. One, of sudden onset, occurred in epidemic form (see Wright and Morley, 1958). Children with this syndrome were afebrile, and, though rather somnolent, mentally clear. Wild alternating horizontal movements of the eyes occurred spontaneously, as well as violent agitation of the trunk and limbs on attempting to sit up, or even to raise a leg or arm. There was no disturbance of the C.S.F., and fortunately all the cases recovered in the space of a few days and were left with no immediate sequels.

There were other cases who came in with convulsions and remained unconscious with various pyramidal signs, and in some but not all there was a pleocytosis in the cerebrospinal fluid.

A most interesting group comprised seven children with roughly similar symptoms, in whom there was a sudden onset of hypotonia and weakness of a part of the skeletal musculature. Tendon reflexes were preserved or exaggerated. Flaccidity was so profound that in a bad case the child could not even sit up or hold the head steady. In some there was elevation of cell count or protein level in the cerebrospinal fluid. There were no sensory changes, and these children tended to recover but might relapse. The picture was complicated, however, by the fact that hemiplegia occurred in at least one of them and was permanent, while in others flaccid palsy of one or more limbs persisted. One of these children died of respiratory failure. A number of children were observed who had the permanent residua of illnesses that sounded like encephalitis. Some had convulsions, some mental backwardness, as well as a group with parkinsonism and other basal ganglionic disorders, including oculogyric crises, suggesting a kinship with encephalitis lethargica. The label 'acute poliomyelitis' must be used with caution, but we saw some children who developed flaccid palsies of a number of muscle groups in the limbs during a febrile illness with a mixed pleocytosis in the cerebrospinal fluid, and in some out-patients an isolated flaccid palsy of the limbs of abrupt onset underwent the same sequence of gradual but often incomplete recovery that we are familiar with in poliomyelitis.

It is difficult to say if mental deficiency of primary type is more or less common than in Britain. There are certainly many examples. During the year about 10 mongols were seen. Much mental deficiency is acquired after inflammatory processes in the nervous system, and we diagnosed one defective child on clinical grounds as a case of toxoplasmosis. Two cases of microcephaly were seen. I did not see a cretin during the year. A number of cases of primary cerebral agenesis with palsy were also seen.

Recurrent convulsions in children are not a reason for bringing them to out-patients in Ibadan; in Britain such cases form an important part of clinic work. 
Diseases of Genito-Urinary System. Nephrosis is one of the big clinical problems among Ibadan children but it is not encountered much in adults. Such cases present as a Type 2 nephritis, with proteinuria and oedema, without cell deposit in the urine, nor any nitrogen retention. Some of them go on to develop hypertension and azotaemia in a year or more. Some seem to remit quickly and spontaneously, and it was my impression that these remissions were assisted by using penicillin in the first stages. The prognosis for recovery may be better than in British children and several returned as far as can be judged to normal, without residual proteinuria, within a year. A large number continue to run a fluctuating course in out-patients, and their eventual fate remains to be seen. There is nothing in the preceding history of these children that appears to account for the onset of nephrosis. A few start as young as 2 years, but most have been between 3 and 6 . Whether the reputed association between quartan malaria and nephritis has any relevance is a matter worth investigating. The infection rate among this group of oedematous children was very low, which contrasts with their susceptibility to pneumococcal infections in Great Britain. Type 1 nephritis, though encountered, was unusual.

Diseases of Bones and Joints. Acute osteomyelitis in young children was very common. A multifocal infection involving simultaneously many bones in several limbs, usually without much systematic upset except some fever, was a frequent and interesting condition. Sometimes there was an associated septic arthritis, or subcutaneous abscesses. The staphylococcus accounted for the majority, but as already mentioned, Salmonella was a common pathogen when the child also suffered from sickle cell anaemia. Radiographic changes were early and gross. The mandible was sometimes involved, and the ribs, but predominantly the limb bones. The fairly benign course is reflected in the single death out of 26 cases. Nevertheless, it was often weeks before pus ceased to form at the site of bony swelling, and several patients ran through a wide range of antibiotics before recovery. With the exception of occasional sequestrectomy, surgical measures were seldom necessary; even where sinuses formed, eventual healing occurred. Amyloid disease was not seen in any child during the year.

Acute septic arthritis affected children under 3 years of age. Very often it was an extension of a neighbouring osteomyelitis, but sometimes the joint involvement was primary and the process was then frequently multiple. Surprisingly, intense pain was rarely present and again we were struck by the comparative absence of constitutional illness. These children did well after aspiration of pus from the joints and appropriate chemotherapy; most of them too were infected with the staphylococcus.

Purulent Meningitis. There were 36 cases of acute meningitis and a causative organism was not identified in 15 of them. Preliminary out-patient treatment with penicillin or a sulphonamide may have been sometimes given, but even so the failure rate seems surprisingly high. Of those we did identify, eight were due to Haemophilus (seven of these under 1 year old), and another eight to Pneumococcus (six of whom were infants). Two infants died of $E$. coli meningitis. In the whole series there was only one meningococcal infection, but possibly this organism was one of those that failed to grow in culture. However, it is wellknown that meningococcal meningitis is a scourge in the drier northern parts of Nigeria, and is much less prevalent in the South. With 13 deaths, we cannot be very proud of our results. Many of the cases were advanced when we got them. There was one case of Ps. pyocyanea meningitis, and one due to Haemophilus bronchisepticus.

Tumours. This group differed little from what might be encountered in a British children's hospital. The strawberry naevus, so common in British babies, was not seen during the year. There were examples of nasopharyngeal lymphosarcoma and bilateral ovarian carcinomata, both of which seem to be of relatively high incidence around Ibadan.

Other Nutritional and Deficiency Diseases. A large number of our patients were chronically underfed. It was only where the resulting emaciation was of such a degree as to require urgent admission to hospital that they appear in this analysis. There were 18 such cases. Very often the mother was herself in poor condition and attempting to feed twins. If she believes that her breast milk is insufficient a very watery maize pap is provided as a supplement, and on this it would be difficult to gain weight. As important as deficiency in food is deficiency of water, and many of these malnourished babies were dehydrated; another reason for their admission. Some marasmic infants, with no other cause than underfeeding, would weigh no more than 7 or $8 \mathrm{lb}$. at a year old. Vomiting from underfeeding does not seem to happen as in Britain. In fact, vomiting in babies, whether with gastro-enteritis, feeding 
difficulties or parenteral infections, was strikingly infrequent.

Of the vitamin deficiencies, only two were recognized. These were rickets and riboflavin deficiency. The latter was seen as soreness of the tongue with angular stomatitis. Rickets is not very uncommon in Ibadan children, as Jelliffe (1955) has previously pointed out. Most cases were picked up in infants of about 3 months old. A number of these had been premature, and others shielded from the light as for example by their mothers being in purdah. The main pathogenesis, in fact, was prematurity with overclothing. Some florid examples were seen, but easily corrected with calcium and vitamin $D$.

Cardiac and Circulatory Disease. No case of acute rheumatism was recognized in 1956. Congenital heart disorders were probably encountered less frequently than in a comparable child population in the United Kingdom. For example, no severely handicapped heart case was seen among the 6,000 hospital births in the year. There were seven cases of what we have termed "cardiomegaly with heart failure'. Broadly speaking, there are two varieties of this obscure malady, which is common among both children and adults in the locality. The first group consists of rather quiet hearts that are generally enlarged and that present first with congestive failure. There are few or no murmurs and the failure can be compensated after rest in bed and the use of digitalis, but the life of the child is subsequently very precarious and his exercise tolerance severely restricted. Follow-up is not long enough to establish how long these children live after this sequence has taken place. In the other group the hearts are also large, but there is a severe lesion of the mitral valve which is always incompetent and sometimes stenosed. Invariably there are signs of pulmonary hypertension. Some of these too, have been in failure, but others have come to light only when the children were examined for other disorders. That this is an acquired disorder is virtually certain. Nearly all are upwards of 3 years old. There was nothing suggestive of acute rheumatism in these children, who were afebrile, not anaemic, not ill, and younger at onset than is the case with European acute rheumatism. One died in what appeared to be an exacerbation of a chronic cardiopathy, and at necropsy some pericarditis was found, besides endomyocardial fibrosis with thickening and distortion of the mitral valve and the adjacent endocardium. Both the clinical and post-mortem appearances are precisely those of endomyocardial fibrosis as first described by Bedford and Konstam
(1946) and in more detail by Williams, Ball and Davies (1954) in East Africa. This is the commonest form of heart disease of young people in tropical Africa. Its aetiology is still quite obscure. Certain other cases of this disorder were seen and followed in out-patients. There is little that one can do to help, though it is of course important to map the natural history of this disease in childhood, but we did get the impression that digitalis was useful for some of the patients who were on the brink of congestive failure.

Neonatal Diseases. Seven infants, all aged less than a week, were admitted with a very deep jaundice and two of these died. The local causes of neonatal jaundice have not been elucidated. Some babies, I think, were merely suffering from physiological jaundice aggravated by an inadequate fluid intake. Others may have been cases of infectious jaundice such as are recorded elsewhere in this analysis. Although we made some attempt to exclude haemolytic disease of the newborn by Coomb's tests and never discovered it, one cannot be sure that there were not examples of this disease among our infants. The very high level of rhesuspositive blood groups among this population makes the chance of rhesus incompatibility between mother and child much lower than in Britain.

Immaturity at birth is a great addition to the many physical dangers attending the growth of an African child. Premature birth is nevertheless a very frequent event in Africa. During the year under review 169 infants (not included in the table of admissions) were reared in a premature nursery attached to the Maternity Department. All of

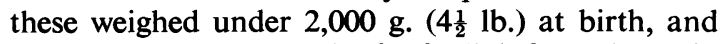
comprised about one half of all infants born in hospital in this weight category. (Of the 6,000 annual births in hospital some 850 were under $5 \mathrm{lb}$. birth weight.) Two thirds of these premature births were twin births (the incidence of twinning is $4.2 \%$ of all births). It may be said that in the early weeks by using the simplest methods it is possible to obtain in Africa survival rates nearly as gratifying, weight for weight, as in Europe or America. The figures are improved because the gestation period of an African baby of given birth weight has usually been longer than that of the European. Most were spontaneous premature deliveries. There was a lessened risk of death within the first 48 hours of life by comparison with European figures, possibly accounted for by the infrequency of lethal congenital malformation, of haemolytic disease of the newborn, of the alveolar membrane syndrome and of severe chilling after 
birth. In spite of a congested nursery and a rapid turnover, sepsis occurred in only $14 \%$ of babies; it was mainly as in Britain of skin and eyes. In spite of the tropical climate the temperature of small babies tended to fall, and sclerema neonatorum was several times encountered; chilling was a more frequent event than overheating. We are unfortunately almost totally ignorant of the later career of these babies after leaving hospital.

Diseases of Liver. Cirrhosis of the liver, though an important entity in adult practice in Ibadan, was unusual in children, and there are only four examples in the series. If protein malnutrition had this sequel we would be certain to see more cases in older children.

Diseases of Eyes. Corneal ulceration is not a condition that finds its way into hospital very much, which accounts for the fact that we only list four cases here. Corneal ulcers, however, are a big factor in the morbidity of children in this area, and they happen not infrequently during infectious illnesses, especially if the child's nutrition is reduced. It is distressing to see how many children in the streets have corneal nebulae, and of course in the northern provinces of Nigeria trachoma adds to the high incidence of blindness in West African young people. Phlyctenular conjunctivitis may go on to ulceration, and corneal opacities also derive from this. The sequel to corneal ulcer is only too often perforation and shrinkage of the eye and blindness.

Poisoning and Idiosycrasy to Drugs. Very few cases of poisoning came into hospital. Kerosene came first as an agent with three victims, and then accidentally-swallowed caustic alkali. There was another group who were said to be suffering from 'native medicine poisoning'. Undoubtedly a large number of our children, especially those who had had convulsions, smelt strongly of an ammoniacal mixture containing urine, which is used in Ibadan as a medicine. Just how important this is in producing symptoms I am not sure. Some of these children, certainly, remained limp and unconscious and died. Others, however, smelling no less strongly and appearing no less ill, recovered and it is my feeling that the native medicine really plays a rather insignificant role. Further south, nicotine and other alkaloids are employed in native medicines, and potent agents may sometimes be given to children here, but the onus of proof that these neurological symptoms are a result of attempted treatment rather than of the disease itself still rests with the exponents of this idea.

\section{Final Remarks}

Certain conditions commonly met with in European practice were encountered too seldom to figure as important. Examples are streptococcal infections and their complications, asthma and kindred psychosomatic disorders, the collagen disorders and some others already referred to. Certain congenital defects were less common than in England, and no case of congenital pyloric stenosis was seen during the year. Nevertheless, the above account demonstrates that we were not confronted in Nigeria with a continuous parade of children suffering from tropical disease in the generally understood sense, nor was the common paediatric currency of England by any means superseded. Though it was true that more than one pathological condition was often present in our young patients it was seldom difficult to disentangle them, or to determine which was dominant in a given clinical situation. In this respect tropical practice among children is less confusing perhaps than among adults, in whom long-standing processes tend to blur the clinical outline of disease.

When the range of normal in all the territories of clinical and laboratory medicine is as yet unmapped and prevailing methods of treatment for many disorders are so discouraging, a great need exists for the collection of data and for clinical research. The teaching of medical students demands an imaginative adaptation of European techniques to fit the widely different local situation. Besides all this, there is the insistent tumultuous pressure of patients, who by their very numbers have power to submerge the medical staff beneath a horizonless sea of routine. Here is opportunity indeed for those with vision and talent, and many will be needed if standards of paediatrics throughout tropical Africa are to be enabled quickly to rise.

\section{REFERENCES}

Bedford, D. E. and Konstam, G. L. S. (1946). Brit. Heart J., 8, 236. British Medical Journal (1956). Editorial. Brit. med. J., 1, 390. Garlick, J. (1956). Personal communication.

Golding, J. S. R. (1956). Ann. roy. Coll. Surg. Engl., 19, 296.

Henshaw, J. E. (1955). West Afr. med. J., 4, 175.

Jelliffe, D. B. (1955). Infant Nutrition in the Subtropics and Tropics. W.H.O. Monograph Series, No. 29. Geneva.

Omololu, O. (1956). J. Univ. Coll. Hosp. (Ibadan), No. 2.

Walters, J. H. (1956). Personal communication.

Williams, A. W., Ball, J. D. and Davies, J. N. P. (1954). Trans. roy. Soc. trop. Med. Hyg., 48, 290.

Wright, J. and Morley, D. C. (1958). Lancet, 1, 871. 